\title{
Analisis Permintaan Bubuk Kayu Manis Indonesia di Pasar Dunia
}

\section{(Demand Analysis of Indonesia Cinnamon Powder in the International Market)}

\author{
Dian Indri Annisa ${ }^{1 *}$, Amzul Rifin $^{2}$, Tanti Novianti ${ }^{2}$ \\ (Diterima Desember 2020/Disetujui Mei 2021)
}

\begin{abstract}
ABSTRAK
Bubuk kayu manis (kode HS 090620) adalah salah satu produk turunan rempah yang paling banyak diekspor oleh Indonesia dan volumenya menurun dalam beberapa tahun terakhir dibandingkan negara pesaingnya, yaitu Vietnam. Analisis permintaan dilakukan untuk menilai posisi persaingan pasar bubuk kayu manis Indonesia di pasar dunia menggunakan metode almost ideal demand systems. Hasilnya menunjukkan bahwa pada pasar Amerika Serikat dan Jerman, Indonesia menjadi eksportir tebesar, sedangkan pada pasar Kanada, bubuk kayu manis Vietnam menempati posisi tertinggi. Berdasarkan elastisitas permintaan, bubuk kayu manis Indonesia adalah produk yang bersifat inelastis dan saling bersubtitusi dengan pesaingnya, yaitu Vietnam di pasar importir Amerika Serikat, Jerman, dan Kanada. Agar dapat terus berdaya saing dalam perdagangan bubuk kayu manis, perlu ada perbaikan mutu produk sesuai dengan sertifikasi internasional serta menjalin kerja sama bilateral.
\end{abstract}

Kata kunci: almost ideal demand systems model, bubuk kayu manis, pasar, persaingan

\section{ABSTRACT}

Cinnamon powder (HS code 090620) is a derivative spice product that is the most exported by Indonesia and is declining in terms of volume in recent years compared to Vietnam, the competitor. This demand analysis aims to assess the market competition for Indonesian cinnamon powder in the world market using the almost ideal demand systems method. The results showed that in the United States and Germany markets, Indonesia is the largest, but in the Canadian market, Vietnamese predominants. Based on the demand elasticity, the Indonesian product is an inelastic and mutually substituting product regarding Vietnam's in the importing markets of the United States, Germany, and Canada. To continue to be competitive in cinnamon powder trading, it is necessary to improve the product quality in addition to the international certification, as well as bilateral cooperation.

Keywords: almost ideal demand systems model, cinnamon powder, competition, market

\section{PENDAHULUAN}

Rempah merupakan komoditas ekspor Indonesia yang potensial untuk dikembangkan; sumbangannya $0,39 \%$ dari total nilai ekspor nonmigas (Kemendag 2019). Data BPS (2019) menunjukkan bahwa dari kurun waktu 2014-2019, harga tertinggi yang didapat dari sektor rempah-rempah adalah pada tahun 2015, yaitu USD 835.722 dan terendah di tahun 2014, yaitu USD 602.128. Salah satu rempah yang menjadi unggulan adalah kayu manis. Pada penelitian Nurhayati (2018), rempah Indonesia yang berpeluang ekspor tinggi di antaranya adalah lada, kayu manis, cengkeh, pala, lawang, dan kapulaga. Rempahrempah tersebut berdaya saing dan memiliki keunggulan kompetitif pada pangsa pasar rising star, yaitu Malaysia, Kanada, Turki, Brazil, Amerika Serikat,

1 Sekolah Pascasarjana, Program Studi Agribisnis, Fakultas Ekonomi dan Manajemen, Institut Pertanian Bogor, Bogor 16680

2 Departemen Agribisnis, Fakultas Ekonomi dan Manajemen, Institut Pertanian Bogor, Bogor 16680

* Penulis Korespondensi: Email: dian_24@apps.ipb.ac.id dan Republik Dominika. Produsen utama dari tanaman kayu manis Indonesia tersebar di Pulau Jawa, Pulau Maluku, dan Pulau Sumatera terutama pada Provinsi Sumatera Barat dan Provinsi Jambi (Pribadi 2016; Kemendag 2017).

Kayu manis Indonesia diekspor dalam bentuk mentah dan dalam berbagai macam produk turunan di antaranya kayu manis tidak dihancurkan (kode HS 090611), bunga kayu manis tidak dihancurkan (kode HS 090619), dan bubuk kayu manis (kode HS 090620). Bubuk kayu manis adalah produk yang terbanyak diekspor oleh Indonesia. Di negara-negara importir, kayu manis selanjutnya digunakan sebagai campuran minuman, bahan dasar kosmetik, serta sebagai minyak atsiri. Permintaan bubuk kayu manis terbesar berasal dari Amerika Serikat, Jerman, dan Kanada.

Volume ekspor bubuk kayu manis Indonesia menurun dalam tahun 2014-2019 (Tabel 1). Pada Gambar 1, dapat dilihat pada kondisi impor bubuk kayu manis dunia cenderung meningkat dalam lima tahun terakhir, akan tetapi dibandingkan dengan ekspor, cenderung menurun. Penurunan ekspor yang terus menerus menyebabkan defisit dalam neraca 


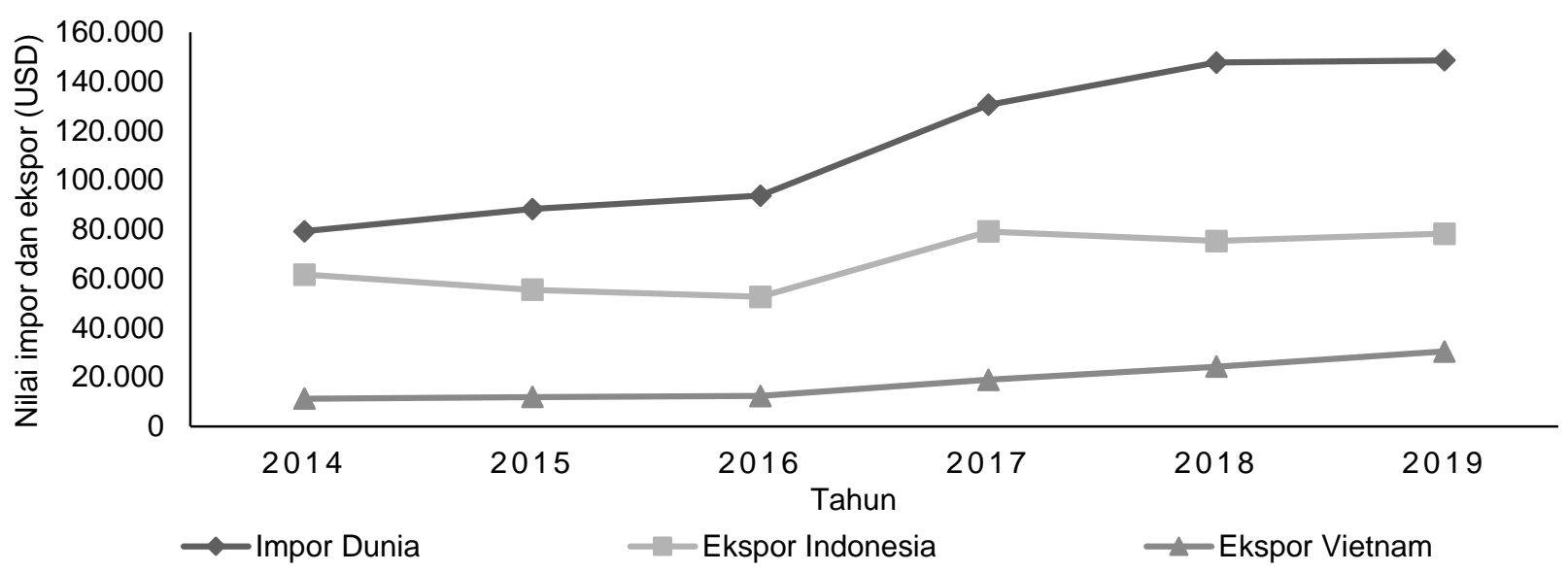

Gambar 1 Gambaran ekspor terhadap impor bubuk kayu manis Indonesia.

(Sumber: ITC 2020).

Tabel 1 Nilai impor bubuk kayu manis Indonesia di pasar Amerika Serikat, Jerman, dan Kanada

\begin{tabular}{lcccc}
\hline \multirow{2}{*}{ Negara Eksportir } & \multirow{2}{*}{ Tahun } & \multicolumn{3}{c}{ Negara Importir (USD) } \\
\cline { 3 - 5 } & & Amerika Serikat & Jerman & 1.603 \\
& 2014 & 10.271 & 2.938 & 1.372 \\
& 2015 & 9.682 & 2.039 & 1.678 \\
& 2016 & 11.798 & 2.094 & 1.499 \\
& 2017 & 29.425 & 3.316 & 1.714 \\
Vietnam & 2018 & 23.823 & 3.046 & 1.859 \\
& 2019 & 31.866 & 2.154 & 1.274 \\
& & & 280 & 1.345 \\
& 2014 & 4.819 & 52 & 1.309 \\
& 2015 & 5.326 & 342 & 2.202 \\
& 2016 & 6.704 & 511 & 2.868 \\
\end{tabular}

perdagangan. Selain itu, saat terjadi penurunan, negara pesaing akan berkompetisi untuk dapat mengisi permintaan dari negara importir, akibatnya pangsa pasar Indonesia akan berkurang. Menurut Jamilah et al. (2012), penurunan permintaan dapat berimplikasi pada harga ekspor di pasar internasional sehingga jika hal ini tidak diperbaiki, maka turunnya nilai dan kuantitas ekspor akan berakibat pada harga barang itu sendiri menjadi tidak menentu. Penelitian ini ingin menelusur penyebab menurunnya ekspor bubuk kayu manis Indonesia dilihat dari permintaan impornya di pasar dunia.

Permintaan pada penelitian ini dianalisis untuk memperoleh infromasi terkait gambaran pangsa pasar bubuk manis Indonesia di pasar dunia. Ketatnya persaingan di antara eksportir membuat Indonesia harus memperbaiki mutu sehingga penting menjaga kuantitas agar permintaan terus naik. Menurut Hermawan (2015), menurunnya ekspor memerlukan upaya perbaikan kebijakan, baik itu dengan mengubah strategi maupun dengan promosi komoditas andalan ekspor Indonesia. Kebijakan ini didukung untuk memproteksi produsen domestik dalam menghadapi persaingan. Berdasarkan latar belakang dan permasalahan yang dihadapi, dalam menganalisis permintaan bubuk kayu manis Indonesia di pasar dunia digunakan model almost ideal demand systems (AIDS) dengan pendekatan elastisitas.

\section{METODE PENELITIAN}

Jenis data yang digunakan adalah data panel, yang terdiri atas data cross section, meliputi data bubuk kayu manis di antaranya negara Indonesia dan Vietnam di pasar Amerika Serikat, Jerman, dan Kanada, serta data deret waktu, yaitu data kuartal pada tahun 2007-2019. Sumber data dalam penelitian ini adalah International Trade Center (ITC). Analisis menggunakan model AIDS.

Model AIDS pada penelitian ini dituliskan sebagai berikut:

$$
\begin{aligned}
& W_{\text {ind }}=\alpha_{1}+\gamma_{1} \ln P_{\text {ind }}+\gamma_{2} \ln P_{\mathrm{vn}}+\beta_{1} \ln \left(\frac{X}{P *}\right) \\
& W_{\mathrm{vn}}=\alpha_{2}+\gamma_{3} \ln P_{\text {ind }}+\gamma_{4} \ln P_{\mathrm{vn}}+\beta_{2} \ln \left(\frac{X}{P *}\right)
\end{aligned}
$$

Keterangan:

$W_{\text {ind }}$

= Share ekspor bubuk kayu manis Indonesia ke pasar Amerika

Serikat/Jerman/Kanada

$W_{\mathrm{vn}} \quad$ S Share ekspor bubuk kayu manis 
Vietnam ke pasar Amerika

Serikat/Jerman/Kanada

$P_{\text {ind }} \quad=$ Harga bubuk kayu manis Indonesia

$P_{\mathrm{vn}} \quad=$ Harga bubuk kayu manis Vietnam

$\alpha_{1}, \alpha_{2} \quad=$ Intersep

$\gamma_{1}, \gamma_{2}, \gamma_{3} \ldots \gamma_{\mathrm{n}} \quad=$ Koefisien

$x \quad=$ Total nilai impor bubuk kayu manis

Indonesia/Vietnam

$p^{*} \quad=$ Indeks harga geometric

Stone $\quad=\sum$ wi.pi

Dalam mengestimasi parameter $\alpha_{i}, Y_{\mathrm{ij}}$, dan $\beta_{\mathrm{i}}$ pada persamaan terdapat beberapa batasan teoretis. Batasan ini digunakan agar model yang digunakan dapat memenuhi beberapa asumsi dari fungsi permintaan, seperti berikut.

1. Adding up: kondisi saat total pengeluaran pada fungsi permintaan sama dengan total pendapatan atau jumlah permintaan sama dengan pengeluaran, dengan rumus:

$$
\sum_{i=1}^{n} \alpha_{i}=1, \sum_{i=1}^{n} \gamma_{i j}=0, \sum_{i=1}^{n} \beta_{i}=0
$$

2. Homogenitas: kondisi saat permintaan berderajat nol dalam harga dan pengeluaran atau saat pendapatan harga berubah pada kondisi yang sama, permintaan barang tersebut tidak berubah, dengan rumus:

$$
\sum_{i=1}^{n} \gamma_{i j}=\mathbf{0}
$$

3. Simetris: penurunan harga silang dari permintaan bersifat simetri baik itu dengan menggunakan elastisitas harga sendiri, elastisitas harga silang, dan elastisitas pengeluaran.

$$
\mathcal{\gamma}_{i j}=\gamma_{j i}
$$

Selanjutnya, menghitung elastisitas dapat menggunakan elastisitas harga sendiri, elastisitas silang, dan elastisitas pengeluaran. Pada penelitian ini, elastisitas yang dilihat adalah sebagai berikut:

1. Elastisitas harga sendiri:

$$
\boldsymbol{e}_{i j}=-\boldsymbol{\delta}_{i j}+\frac{y_{i j}}{w_{i}}-\beta i\left(\frac{W_{j}}{W_{i}}\right)
$$

2. Elastisitas harga silang:

$$
e^{*}{ }_{i j}=-\delta_{i j}+\frac{y_{i j}}{w_{i}}+w_{j}
$$

3. Elastisitas pengeluaran:

סij adalah delta Kronecker.

\section{HASIL DAN PEMBAHASAN}

\section{Kinerja Produksi dan Kualitas Kayu Manis Indonesia}

Potensi sumber daya alam, teknologi, tenaga ahli, serta potensi pasar yang memadai menjadikan Indonesia sebagai produsen utama kayu manis dan berdaya saing tinggi. Indonesia merupakan produsen terbesar kayu manis dunia dalam kurun waktu 20152019, terakhir iikuti oleh pesaingnya Cina, Vietnam, dan Sri Langka (Gambar 2). Sebagai produsen terbesar, Indonesia mengekspor hampir 60\% dari produksi di mana sebagian besar berasal dari Sumatera Barat dan Kabupaten Kerinci, Provinsi Jambi (Ferry 2013, Iswarini \& Iskandar 2013).

Bubuk kayu manis juga berpeluang besar untuk dikembangkan di negara-negara seperti Amerika Serikat, Jerman, dan Kanada. Di pasar Amerika Serikat, pertumbuhan kuantitas ekspor bubuk kayu manis Indonesia dari tahun 2015-2016 adalah 27\% meningkat pada tahun 2016-2017 menjadi 67\%. Tahun 2017-2018 menurun sebesar 26\% dan meningkat dari tahun 2018 ke tahun 2019, sebesar 13\%. Negara importir lain seperti Jerman mengalami pertumbuhan kuantitas yang cenderung menurun. Pada tahun 2015-2016 hanya 20\%, menurun $17 \%$ pada tahun berikutnya. Tahun 2017-2018 terus menurun $15 \%$ dan dari tahun 2018 ke tahun 2019 menurun $21 \%$. Begitupun juga dengan di Kanada yang cenderung menurun. Tahun 2015-2016 menurun 7\%. Pada tahun 2016-2017 meningkat 15\%. Tahun 20172018 meningkat $18 \%$ dan menurun dari tahun 2018 ke tahun 2019 sebesar 4\%. Pertumbuhan ekspor yang berbeda-beda di setiap negara memerlukan perbaikan mutu dan standar produk yang sesuai dengan permintaan pasar agar dapat merebut pasar dan berkompetisi dengan pesaing.

\section{Perilaku Permintaan Bubuk Kayu Manis pada Pasar Amerika Serikat}

Pasar Amerika Serikat merupakan pasar tujuan ekspor utama bubuk kayu manis. Dari hasil olahan data, diketahui bahwa Indonesia memiliki pangsa pasar $64,63 \%$, Vietnam $21,33 \%$, dan rest of the world (ROW) sebesar 14,04\%. Sebagai pangsa pasar utama, Indonesia menjadi pemasok terbesar di negara Amerika Serikat. Sesuai dengan temuan Mubarokah (2016), pasar Amerika Serikat menempati posisi rising star dengan pertumbuhan pangsa ekspor bubuk kayu manis Indonesia sebesar 0,899\% yang artinya bubuk kayu manis asal Indonesia berdaya saing di pasar Amerika Serikat.

Pada Tabel 2 dapat dilihat bahwa pada nilai elastisitas pengeluaran, produk bubuk kayu manis Indonesia bersifat inelastis artinya apabila terjadi perubahan pengeluaran maka tidak terdapat perubahan permintaan dari Amerika Serikat untuk 


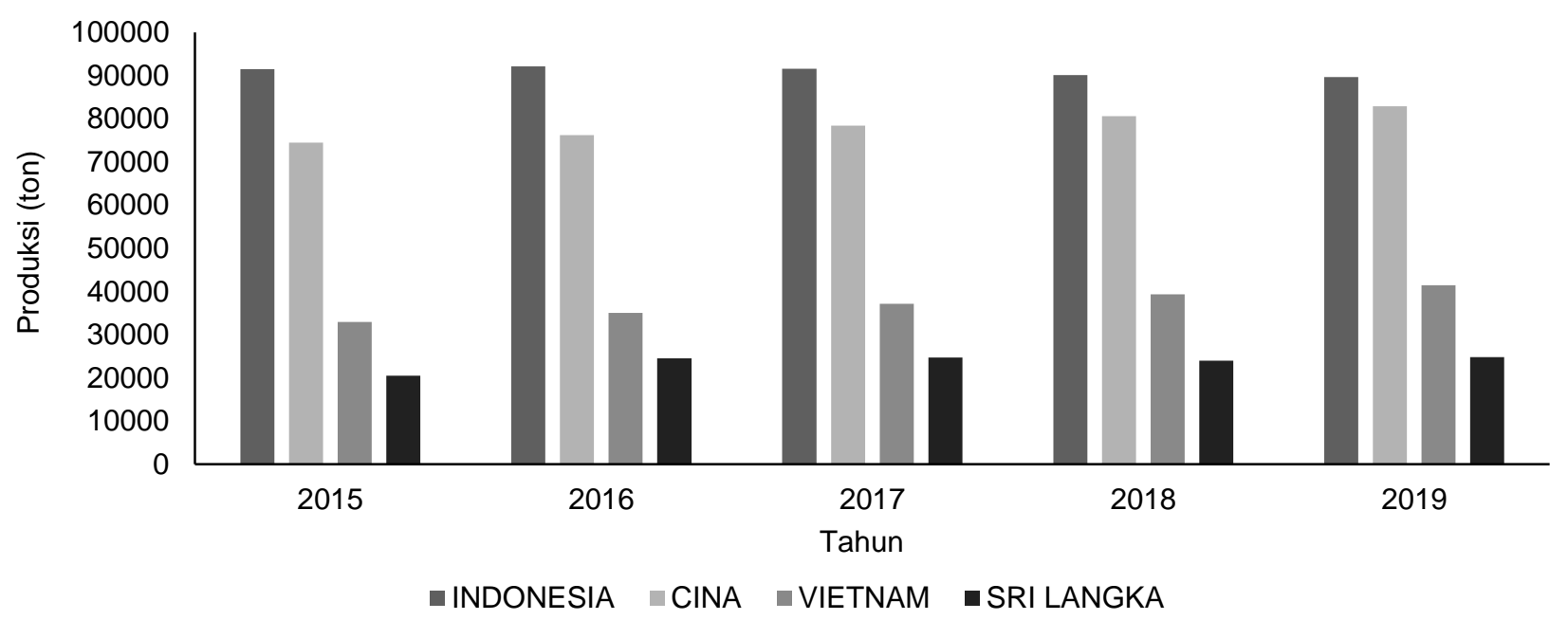

Gambar 2 Negara produsen utama kayu manis dunia. (Sumber: FAOSTAT (2019) (diolah)).

komoditas tersebut dibandingkan Vietnam. Hal ini juga dilihat proporsi pasar bubuk kayu manis Indonesia yang lebih besar dibandingkan Vietnam sehingga saat pasar Amerika Serikat mengalami kenaikan permintaan impor, maka Indonesia akan mengalami kenaikan kuantitas permintaan bubuk kayu manis dan Vietnam mengurangi kuantitasnya.

Produk bubuk kayu manis Vietnam yang bersifat inelastis dilihat dari elastisitas harga sendiri, menggambarkan bahwa permintaan produk tersebut berpengaruh sedikit pada perubahan harga bubuk kayu manis di Vietnam. Produk pertanian cenderung merupakan produk kebutuhan pokok yang kebutuhannya akan ada setiap hari sehingga saat tejadi kenaikan harga atau penurunan harga, perubahan permintaan yang terjadi akan sangat kecil. Kayu manis merupakan barang yang bersifat inelastis sehingga perlu dijaga stabilitasnya (Mubarokah 2020).

Berdasarkan Tabel 3, diketahui hubungan elastisitas silang bubuk kayu manis Indonesia dengan Vietnam bernilai positif atau saling bersubstitusi. Menurut penelitian Nguyen et al. (2018), produk rempah asal Asia bersifat inelastis dan saling bersubstitusi di pasar Amerika Serikat. Harga rempah dari negara Asia tidak memengaruhi impor di pasar Amerika serikat sehingga permintaan akan terus ada secara signifikan. Indonesia menjadi produsen utama di pasar Amerika Serikat dan hubungan positif ini menunjukkan setiap negara saling berkompetisi untuk mendapatkan pangsa pasar di Amerika Serikat.

\section{Perilaku Permintaan Bubuk Kayu Manis pada Pasar Jerman}

Jerman adalah pangsa tujuan ekspor bubuk kayu manis dunia terbesar di Uni Eropa (Kemendag 2015). Indonesia memiliki pangsa pasar $24,72 \%$ dan Vietnam $3,99 \%$ dari rest of the world (ROW) yang $71,30 \%$. Menurut Kemendag (2015), rempah-rempah termasuk kayu manis, lada, pala, dan vanili baik yang utuh
Tabel 2 Elastisitas pengeluaran dan harga sendiri bubuk kayu manis di pasar Amerika Serikat

\begin{tabular}{lcc}
\hline \multicolumn{1}{c}{ Negara } & $\begin{array}{c}\text { Elastisitas } \\
\text { pengeluaran }\end{array}$ & $\begin{array}{c}\text { Elastisitas } \\
\text { harga sendiri }\end{array}$ \\
\hline Indonesia & 0,9886 & $-0,8686$ \\
Vietnam & 1,0891 & $-0,6842$ \\
\hline
\end{tabular}

Tabel 3 Elastisitas silang bubuk kayu manis di pasar Amerika Serikat

\begin{tabular}{lrc}
\hline \multicolumn{1}{c}{ Negara } & Indonesia & Vietnam \\
\hline Indonesia & - & 0,0860 \\
Vietnam & 0,2605 & \\
\hline
\end{tabular}

Tabel 4 Elastisitas pengeluaran dan harga sendiri bubuk kayu manis di pasar Jerman

\begin{tabular}{lcc}
\hline \multicolumn{1}{c}{ Negara } & $\begin{array}{c}\text { Elastisitas } \\
\text { pengeluaran }\end{array}$ & $\begin{array}{c}\text { Elastisitas } \\
\text { harga sendiri }\end{array}$ \\
\hline Indonesia & 0,5597 & $-0,6604$ \\
Vietnam & 1,0176 & $-0,9666$ \\
\hline
\end{tabular}

maupun yang dihaluskan merupakan tanaman rempah yang memiliki pasar yang tinggi di Uni Eropa. Adapun negara-negara penghasil kayu manis yang banyak memenuhi pasar Eropa adalah Sri Langka, Indonesia, Vietnam, dan Cina.

Pada Tabel 4 diketahui bahwa dari nilai elastisitas pengeluaran, Indonesia memiliki elastisitas pengeluaran yang bersifat inelastisis begitupun juga dengan negara Vietnam. Jika dilihat dari kedua nilai elastisitas pengeluaran bubuk kayu manis Indonesia dan Vietnam, produk Indonesia bersifat inelastis dan Vietnam bersifat elastis. Perubahan harga bubuk kayu manis Indonesia yang terjadi di pasar Jerman berpengaruh kecil pada permintaan impor di negara tersebut. Pada elastisitas harga sendiri, Indonesia dan Vietnam bersifat inelastis. Barang bersifat inelastis artinya persentase perubahan harga lebih besar dibandingkan dengan jumlah barang yang diminta (Sukirno 2015). Bubuk kayu manis Indonesia adalah 
produk yang harganya lebih stabil daripada bubuk kayu manis Vietnam. Saat terjadi penurunan permintaan bubuk kayu manis di pasar Jerman, maka akan terjadi perubahan harga pada permintaan bubuk kayu manis Vietnam karena komoditas ini lebih responsif terhadap perubahan harga. Selain diketahui nilai elastisitas pengeluaran dan elatisitas harga, perlu diketahui elastisitas silangnya (Tabel 5).

Berdasarkan nilai elastisitas silang pada pasar Jerman, hubungan Indonesia dengan Vietnam bernilai positif atau bersifat substitusi. Indonesia menjadi eksportir dan pemasok utama bubuk kayu manis di pasar Jerman. Dalam elastisitas silang positif barang bersifat substitusi artinya saat terjadi kenaikan harga suatu barang dapat menaikkan perrmintaan barang lain (Salma et al. 2004). Saat kondisi tingginya permintaan bubuk kayu manis asal Indonesia, maka pesaing akan mengurangi ekspornya ke negara Jerman. Ini menguntungkan bagi Indonesia agar dapat mendapatkan pangsa pasar yang besar untuk produk bubuk kayu manisnya terutama di pasar Eropa seperti Jerman.

\section{Perilaku Permintaan Bubuk Kayu Manis pada Pasar Kanada}

Bubuk kayu manis adalah salah satu potensi besar bagi Indonesia untuk dapat memperbesar pasar di Amerika Utara salah satunya di Kanada. Indonesia dan Vietnam menjadi negara pemasok bubuk kayu manis yang bersaing untuk memperebutkan pasar Kanada. Share pasar bubuk kayu manis Vietnam sebesar $23,23 \%$ sedangkan Indonesia,61\% dari rest of the world (ROW) sebesar $54,16 \%$.

Nilai elastisitas pengeluaran bubuk kayu manis Indonesia dan Vietnam di pasar Kanada bersifat inelastis (Tabel 6). Bubuk kayu manis asal Indonesia lebih responsif terhadap perubahan harga dibandingkan dengan asal Vietnam sehingga saat terjadi perubahan harga di pasar Kanada, maka permintaan produk asal Indonesia akan mendapatkan proporsi yang lebih besar dibandingkan permintaan produk Vietnam yang mengalami penurunan. Pada elastisitas harga sendiri, ditunjukkan bahwa bubuk Indonesia dan Vietnam bersifat inelastis. Hal ini karena Vietnam menjadi eksportir utama bubuk kayu manis di pasar Kanada sehingga di saat terjadi kenaikan harga pada pasar Kanada, maka permintaan impor bubuk asal Vietnam akan tetap ke pasar Kanada. Harga produk Indonesia dipengaruhi oleh perubahan harga dunia sehingga jika harga kayu manis dunia naik maka permintaan impornya akan meningkat; sebaliknya, jika harga kayu manis dunia turun, maka permintaan kayu manis dunia akan turun (Iskandar et al. 2012).

Elastisitas silang Indonesia dengan Vietnam (Tabel 7) menunjukkan hubungan substitusi karena bernilai positif. Pada pasar Kanada, bubuk kayu manis Vietnam lebih mendominasi dibandingkan produk Indonesia. Hal ini dikarenakan terdapat beberapa hambatan bagi Indonesia terutama dari segi mutu; mutu produk
Tabel 5 Elastisitas silang bubuk kayu manis di pasar Jerman

\begin{tabular}{lcc}
\multicolumn{1}{c}{ Negara } & Indonesia & Vietnam \\
\hline Indonesia & - & 0,0137 \\
Vietnam & 0,1968 & - \\
\hline
\end{tabular}

Tabel 6 Elastisitas pengeluaran dan harga sendiri bubuk kayu manis di pasar Kanada

\begin{tabular}{lcc}
\hline \multicolumn{1}{c}{ Negara } & Elastisitas & $\begin{array}{c}\text { Elastisitas } \\
\text { pengeluaran }\end{array}$ \\
& 0,7519 & $-0,8861$ \\
harga sendiri \\
Indonesia & $-0,1683$ & $-0,3304$ \\
\hline
\end{tabular}

Tabel 7 Elastisitas silang bubuk kayu manis di pasar Kanada

\begin{tabular}{lcr}
\hline \multicolumn{1}{c}{ Negara } & Indonesia & Vietnam \\
\hline Indonesia & - & 0,1126 \\
Vietnam & 0,6994 & - \\
\hline
\end{tabular}

Vietnam lebih baik, selain itu pengemasan yang kurang baik juga masih menjadi hambatan dalam produksi.

\section{Implikasi Kebijakan Bubuk Kayu Manis}

Berdasarkan analisis ini, produk bubuk kayu manis Indonesia bersifat inelastis artinya harga tidak memengaruhi jumlah barang yang diminta Amerika Serikat. Sesuai dengan pendapat Nguyen et al. (2018), permintaan rempah asal Asia bersifat inelastis sehingga produk dari negara di Asia menjadi pemasok utama rempah di Amerika Serikat. Bubuk kayu manis Indonesia dengan Vietnam memiliki hubungan yang saling bersubstitusi hal ini mencerminkan tingginya persaingan untuk mendapatkan pangsa pasar di Amerika Serikat, menyebabkan ketatnya persaingan antarnegara eksportir. Maka dari itu, menjaga mutu dan kuantitas produk menjadi hal yang perlu diperhatikan untuk dapat merebut pasar dengan memperhatikan standar mutu. Amerika Serikat menerapkan kebijakan country of origin labeling (COOL), yaitu regulasi dengan pemberian label produk "product of" atau "made in" yang diatur oleh United States Departement of Agriculture (USDA) (Umar et al. 2020). Kebijakan ini dibuat untuk memproteksi produk impor yang masuk ke Amerika Serikat dan menciptakan kondisi persaingan yang sehat.

Bubuk kayu manis di pasar Jerman merupakan produk yang inelastis artinya perubahan harga bubuk kayu manis tidak memengaruhi permintaan pasar Jerman. Sebagai eksportir terbesar bubuk kayu manis, ekspor komoditas ini menurun. Penurunan ini terjadi berkaitan standar kebersihan (sanitary) (CSIS 2015). Selain ada produk yang gagal masuk ke pasar Jerman, produk bubuk kayu manis yang saling bersubtitusi dengan pesaingnya (Vietnam) membuat ketatnya persaingan di antara negara eksportir. Hal ini perlu menjadi perhatian bagi Indonesia sebagai eksportir utama bubuk kayu manis di Jerman agar dapat memperhatikan mutu produknya.

Pada pangsa pasar Kanada, bubuk kayu manis Indonesia bersifat inelastis, artinya perubahan harga tidak memengaruhi permintaan. Hal ini juga didukung dengan meningkatnya permintaan bubuk kayu manis 
di pasar Kanada setiap tahunnya. Kanada merupakan negara dengan beragam budaya termasuk dari Asia, menjadikan rempah-rempah menjadi salah satu kebutuhan mereka seperti untuk bumbu masakan dan campuran minuman. Bubuk kayu manis Indonesia merupakan produk substitusi dengan Vietnam sehingga membuat ketatnya persaingan di antara negara eksportir. Potensi pasar yang besar ini perlu didukung oleh hubungan kerja sama yang baik di antara kedua negara.

\section{KESIMPULAN}

Berdasarkan analisis ini, permintaan akan pasar bubuk kayu manis Indonesia berbeda-beda pada setiap pasar importir dilihat dari elastisitasnya. Bubuk kayu manis adalah produk yang bersifat inelastis, artinya perubahan harga dari negara asal eksportir tidak memengaruhi permintaan di negara tujuan sehingga untuk memperluas pasar, strategi yang perlu dijalankan adalah dengan memperbaiki kualitas produk. Produk bubuk kayu manis Indonesia memiliki hubungan subtitusi atau saling menggantikan dengan pesaingnya di pasar importir Amerika Serikat, Jerman, dan Kanada. Artinya, ketika harga bubuk kayu manis asal Vietnam meningkat, maka Amerika Serikat, Jerman, dan Kanada akan mengalihkan impornya ke Indonesia sehingga menjadi peluang yang baik bagi Indonesia untuk mendapatkan pangsa pasar yang lebih besar.

Perlu ada regulasi pemerintah dan instansi untuk meningkatkan mutu yang berlandaskan Standar Nasional Indonesia (SNI) dengan mengacu pada standar internasional, yaitu The International Organization for Standardization (ISO) (Kristiningrum \& Lukiawan 2011). Produk bubuk kayu manis yang telah memenuhi syarat ekspor, selanjutnya akan disesuaikan dengan kebijakan yang berlaku pada setiap negara. Selain itu, bentuk kerja sama ekonomi bilateral Indonesia dengan negara importir diharapkan dapat membantu meningkatkan ekspor bubuk kayu manis Indonesia ke pasar dunia.

\section{DAFTAR PUSTAKA}

[BPS] Badan Pusat Statistik. 2019. Data Ekspor Pertanian Tahun 2019. [Internet]. Jakarta (ID): [diunduh September 2019] Tersedia pada https://www.bps.go.id/publication/2019/08/29/

[CSIS] Centre for Strategic and International Studies. 2015. Kajian Tentang Dampak Kemitraan (CEPA) Uni Eropa-Indonesia. [Internet] [Diunduh 29 Januari 2021] Tersedia pada https://eeas.europa.eu/ election-observation-missions/eom-zambia2016/4154/kajian-tentang-dampak-perjanjiankemitraan-ekonomi-komprehensif-cepa_en
Ferry Y.2013. Prospek Pengembangan Kayu Manis (Cinnamomun Burmanii $L$ ) di Indonesia. Jurnal SIRINOV 1(1): 11-20.

Hermawan I. 2015. Daya Saing Rempah Indonesia Di Pasar Asean Periode Pra dan Pasca Krisis Ekonomi Global. Buletin Ilmiah Litbang Perdagangan. 9(2): 153-178. https://doi.org/ 10.30908/bilp.v9i2.6

Iskandar S, Jauhari H, Mulyana A, Dewata A, Yamin M, Taufik M. 2012. Analysis of Determinant Factors Influencing Cinnamon Export and Prices in Indonesia. Proceeding The $13^{\text {th }}$ Malaysia Indonesia Conference on Economics, Management and Accounting (MIICEMA).

Iswarini $\mathrm{H}$ dan Iskandar S. Prospek Ekspor Kayu Manis dan Faktor yang Melatarbelakangi Sirup Kayu Manis di Kecamatan Gunung Kerinci Kabupaten Kerinci Propinsi Jambi. Jurnal Societa. 2(2): 48-52.

[ITC] International Trade Centre. 2020. Nilai Ekspor Kayu Manis Tahunan [Internet] [diunduh 4 Juni 2020]. Tersedia pada: https://www. trademap.org/Country_SeIProduct_TS

[ITC] International Trade Centre. 2020. Nilai Impor Kayu Manis Tahunan [Internet]. Jakarta (ID): [diunduh 4 Juni 2020]. Tersedia pada: https:// www.trademap.org/Country_SelProduct_TS.

Jamilah, Sinaga BM, Tambunan M, Hakim DB. 2012. Dampak Perlambatan Ekonomi China dan Devaluasi Yuan Terhadap Kinerja Perdagangan Pertanian Indonesia. Jurnal Ekonomi dan Keuangan. 2(3): 325-345. https://doi.org/ 10.24034/j25485024.y2016.v20.i3.61

[Kemendag] Kementerian Perdagangan Republik Indonesia. 2019. Ekspor 10 Komoditi Potensial Periode 2014-2019. [Internet] [diunduh 2019 November 15]. Tersedia pada : https:// www.kemendag.go.id/id/economic-profile/10-mainand-potential-commodities

[Kemendag] Kementrian Perdagangan. 2015. Market Brief Spices and Herbs di Pasar Jerman [Internet] [diunduh 9 Juli 2020]. Tersedia pada http:// djpen.kemendag.go.id/membership/data/files/0efe 2-spices-hamburg.pdf

Kristiningrum E, Lukiawan R. 2011. Kajian Standar Sektor Rempah-Rempah Terkait Dengan Penolakan Produk Dalam Mendukung Peningkatan Ekspor Indonesia. Jurnal Standarisasi. 13(1): 26-35.

Mubarokah I. 2020. Analisis Pengembangan Ekspor Kayu Manis Indonesia. Jurnal Ecoplan. 3(1): 1-11. https://doi.org/10.20527/ecoplan.v3i1.52

Nguyen LY, Duong LT, Mentreddy RS. 2018. The US Import Demand for Spices and Herbs by Differentitated Sources. Journal of Applied 
Research on Medicinal and Aromatic Plants. 12(2): 13-20. https://doi.org/10.1016/j.jarmap.2018. 12.001

Nurhayati E. Hartoyo S. Multasih S. 2019. Analisis Pengembanagn Pala, Lawang, dan Kapulaga Indonesia. Jurnal Ekonomi dan Pembangunan Indonesia 19(2): 173-190. https://doi.org/ 10.21002/jepi.v19i2.847

Pribadi ER. 2016. Perkembangan Produksi dan Ekspor Kayu Manis Indonesia. Jurnal Penelitian dan Pengembangan Tanaman Industri. 22(2): 10-14.
Salma, Afia I, Susilowati I. 2004. Analisis Permintaan Objek Wisata Alam Curug Sewu, Kabupaten Kendal Dengan Pendekatan Travel Cost. Jurnal Dinamika Pembangunan. 1(2): 153-165.

Sukrino S. 2015. Mikroekonomi Teori Pengantar Edisi Ketiga. Jakarta (ID): PT Rajagrafindo Persada.

Umar H, Evani S. 2020. Ekspor Daging Sapi Kanada Pasca Kebijakan Country of Origin Labelling (COOL) Amerika Serikat Tahun 2009-2015. Jurnal Populis. 5(9): 1327-344. https://doi.org/ 10.47313/ppl.v5i9.829 